\title{
PAPILLARY CARCINOMA OF BREAST-A CASE REPORT
}

\author{
Shashidhar. H. B, Hemalatha. A. L, Suma. J. K, Aparna Ningombam
}

1. Assistant Professor, Department of Pathology, Mysore Medical College and Research Institute, Mysore, Karnataka.

2. Professor and HOD, Department of Pathology, Mysore Medical College and Research Institute, Mysore, Karnataka.

3. Post- Graduate Student, Department of Pathology, Mysore Medical College and Research Institute, Mysore, Karnataka.

4. Post- Graduate Student, Department of Pathology, Mysore Medical College and Research Institute, Mysore, Karnataka.

\section{CORRESPONDING AUTHOR:}

Dr. Shashidhar H B,

Assistant Professor of Pathology,

No. 9 Doctors Quarters, JLB Cross Road, Behind Regaalis Hotel,

Devraj Mohalla, Mysore-577005,

Ph: 0091-9448048774, 0091-821-2422855

E mail ID: shbmysore@gmail.com

\section{ABSTRACT:}

Invasive papillary carcinomas of breast are extremely rare .This case report deals with this rare entity which occurred in a 55yr old woman with a recurrent breast mass. The exceptional features in this case include the younger age at occurrence as compared to the mean age combined with the fact that contrary to the usual good prognosis that these tumors are known to be associated with, the present case had a recurrent tumor following a previous mastectomy.

KEYWORDS: Invasive, Papillary Carcinoma, Breast.

\section{INTRODUCTION:}

Although, papillary forms of intraductal cancers are common components frequently encountered in mammary cancers, invasive papillary carcinomas of breast are relatively rare. Besides this, invasive papillary carcinomas in contrast to the non papillary histologic types are more likely to exhibit some outstanding features like circumscription, cytoplasmic oxyphilia, microcalcification, intermediate histologic grade, moderate or marked mucin production and an associated intraductal component of papillary type1. These tumors are associated with another unique feature in that, the metastases are not commonly found and if present, involve fewer than four lymph nodes. On the contrary, there is a significantly high frequency of marked sinus histiocytosis in the regional lymph nodes. These lesions occur with a significantly high frequency in postmenopausal women.

Papillary carcinomas resemble mucinous and tubular varieties of mammary carcinoma in that, the treatment failure rate is significantly lower in these cancers as compared to any other histological type of breast cancer.

These unique features place the papillary breast cancers in a class apart from the other histological types and make them definitely worthy of the special notice and attention which they richly deserve.

Journal of Evolution of Medical and Dental Sciences/Volume 1/Issue 2/April-June 2012 


\section{CLINICAL SUMMARY:}

A 55yr old woman presented with a swelling over the right chest wall of 6 months' duration. She gave history of a lump in the right breast two years back for which a mastectomy was done following a clinical diagnosis of malignancy. The histopathological examination report was not accessible. Local examination revealed a nodular mass measuring $6 \times 5 \times 4 \mathrm{cms}$ situated lateral to the mastectomy scar which was firm in consistency. There were no palpable axillary or supraclavicular lymph nodes. After fine needle aspiration, a cytodiagnosis stating 'suspicious of malignancy' was offered. The swelling was excised with wide margins and the specimen was subjected to histopathological examination.

\section{PATHOLOGICAL FINDINGS:}

On gross examination, the specimen consisted of a single, irregular, skin covered gray brown mass which measured $14 \times 6 \times 3 \mathrm{cms}$. Cut section revealed an ill defined gray white area which measured $8 \times 2 \mathrm{cms}$ with intervening areas of necrosis.

On microscopy, multiple sections studied from the gray white tumor area showed uniform sized tumor cells arranged perpendicular to a central fibrovascular core. The cells showed cytoplasmic oxyphilia, nuclear hyperchromasia, a high nucleocytoplasmic ratio and increased mitotic activity. The tumor cells were also seen invading the adjacent stroma .Histochemistry for mucin was negative with mucicarmine, alcain blue and Per-Iodic Acid Schiff Stain.

\section{DISCUSSION:}

Papillary carcinoma of breast is a rare neoplasm which accounts for about $1-2 \%$ of breast carcinomas in women and a slightly higher percentage of breast carcinomas in men. Women with papillary carcinoma of breast are usually older than patients with other types of breast carcinomas (mean: 63-67yrs). In the present case, the patient was much younger than the mean age at presentation. The maximum diameter was not in accordance with the average size of papillary carcinoma which is 2-3 cms. Another significant feature of papillary carcinoma is a rounded and well circumscribed appearance on macroscopy. The tumor in the present case report showed a deviation in this regard in that it was irregular. Besides these features, lymph node metastases are not commonly found in papillary carcinomas and if present, involve less than four nodes. On the contrary, there is a significantly high frequency of marked sinus histiocytosis in the regional lymph nodes1.The present case showed concurrent features in this regard in that, no lymph node involvement was seen .

Although, the histopathological features of this tumor are distinct and allow accurate diagnosis, the cytological diagnosis may be problematic as observed in the present case since nuclear pleomorphism is not always marked and naked nuclei may be present 2 . This explains the fact that, the recurrent lesion in the present case was reported as 'suspicious of malignancy'. Some of the papillary carcinomas are known to show areas of cell proliferation which become so dense that the basic papillary patterns are overgrown and such tumors are referred to as solid papillary carcinomas3. Areas with organoid growth patterns, ribbons and trabeculae have also been reported in papillary carcinomas. Collagenisation of stroma leading to the appearance of a radial sclerosing

Journal of Evolution of Medical and Dental Sciences/Volume 1/Issue 2/April-June 2012 
lesion, or foci of intraductal carcinoma may be seen in occasional cases, but none of these features were observed in the tumor described here which exhibited a frank papillary architecture4.

A broad range of intracytoplasmic mucin may be visualized in papillary carcinomas5.The tumor described in the present case report is negative for mucin. Tumors with solid papillary growth pattern may contain grimelius and chromogranin positive neurosecretory type cytoplasmic granules which are usually immunoreactive for synaptophysin and neuron specific enolase and positive for estrogen receptors .Recently more than $50 \%$ of solid papillary carcinomas that were evaluated displayed co-expression of neuroendocrine and apocrine markers thus suggesting that neuroendocrine and apocrine differentiation may co-exist in the same tumor6. Immunohistochemistry was not undertaken in the present case as the tumor did not exhibit any solid papillary growth pattern.

\section{CONCLUSION:}

Papillary carcinomas of breast though rare have a relatively favorable prognosis as compared to the other invasive duct carcinomas of no special type and hence it becomes imperative for every pathologist to be aware of this variant of breast carcinoma as such a distinction is very important. It commands due attention since it represents a unique histologic type of invasive mammary cancer associated with favourable prognosis.

\section{REFERENCES:}

1. Fletcher.C.D.M. Diagnostic pathology of tumors, 2ndedition, Vol.1, London; Churchil Livingstone, 2000.p.898-899.

2. Gray.W.Diagnostic cytopathology.London; Churchil Livingstone, 1995, 280-282.

3. Foote F.W, Stewart F.W.A Histologic classification of carcinoma breast. Surgery 1996;19:74-99.

4. Aptrodite.M, Andreas.C.L, Eftratious.P.96year old woman with a tumorous lesion of right breast. Archives of Pathology and Laboratory Medicine 2004; 129(5):128-129.

5. Edwin.R.F, Alka S.P, Carol R, Brace B, Bernard F. Pathologic findings from the National Adjuvant Breast Project. Am J Clin Pathol 1980; 73:313-322.

6. Cserni.G. "Revertant" mammary solid papillary carcinoma in lymph node metastasis. Pathology Oncology Research 2002;8(1):74-77

\section{ACKNOWLEDGEMENT:}

We thank Dr Geetha Avadhani, Professor \& HOD, Department of Surgery, K.R. Hospital, Mysore Medical College and Research Institute, for her kind support and co-operation.

Journal of Evolution of Medical and Dental Sciences/Volume 1/Issue 2/April-June 2012 


\section{CASE REPORT}

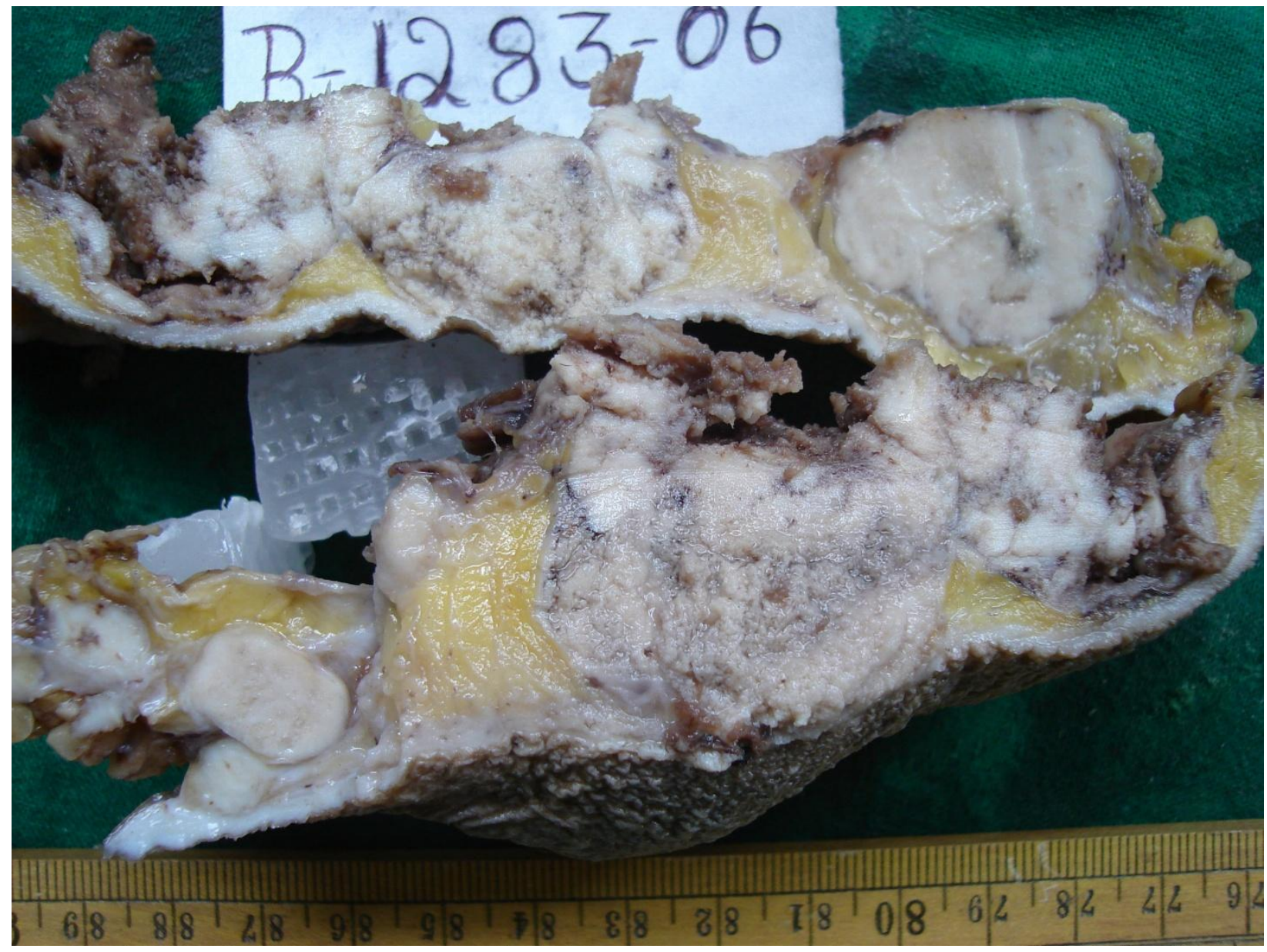

FIG: 1 - Gross - Multiple, solid, gray white, irregular, tumor areas with papillary excrescences. 


\section{CASE REPORT}

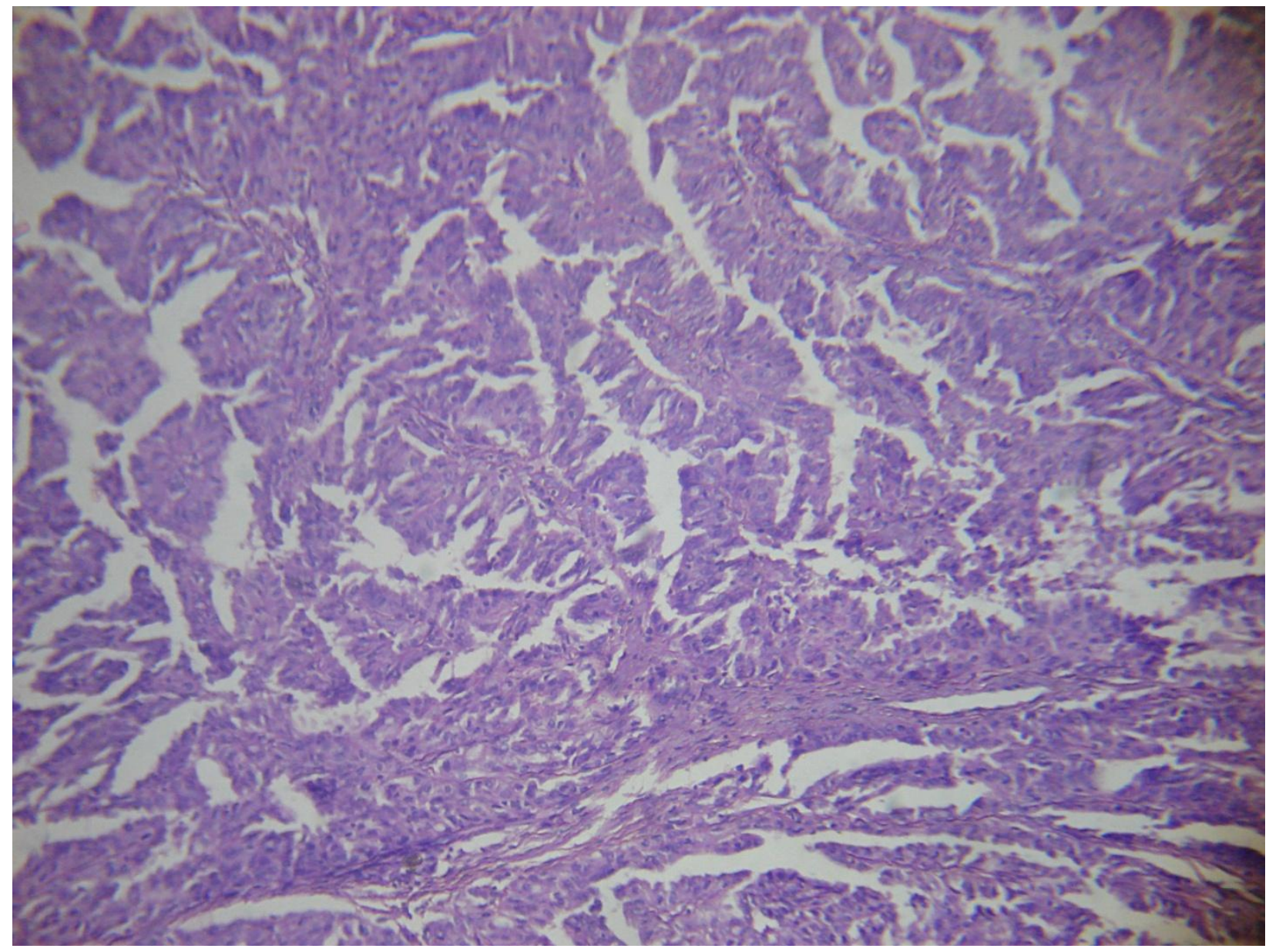

FIG: 2 - Microscopy - Showing papillae lined by pleomorphic tumor cells

(Heamatoxylin and Eosin x 10). 